\title{
Institutional Entrepreneurship in North American Lightning Protection Standards: Rhetorical History and Unintended Consequences of Failure
}

\author{
Professor Sara L. McGaughey
}

Griffith Business School, Griffith University, 170 Kessels Road, Nathan, Queensland 4111, AUSTRALIA.

email: s.mcgaughey@griffith.edu.au

\begin{abstract}
We examine a historical case study of failed institutional entrepreneurship in the context of a mature lightning protection standard developed under the auspices of the National Fire Protection Association (NFPA) in the United States. Particular emphasis is placed on events post 1989 when entrepreneurs who had continuously supported the conventional standard sought to establish a competing standard in parallel. When unsuccessful, they sought to entirely remove the existing standard of almost 100 years. The study shows how failure of institutional work may in fact lead to a strengthening and reproduction of existing institutions and their underlying logics, contrary to the institutional entrepreneurs' intent. It also underscores the potential value of history as an interpretive device and strategic resource for both challengers and custodians of institutions, and moves beyond heroic conceptions of institutional entrepreneurship to recognise the discontinuous, non-linear, collective processes that take place in institutional work.
\end{abstract}

Keywords: Institutional entrepreneurship, institutional work, institutional logics, rhetorical history, standards, lightning protection 


\section{Introduction}

While institutional theory has traditionally emphasised how organisational processes are shaped by institutional forces that reward conformity and reinforce continuity, entrepreneurship has tended to emphasise how opportunities are recognised and institutions themselves shaped by entrepreneurial forces that bring about change. ${ }^{1}$ The juxtaposition of these contradictory forces into the single, dialectical concept - institutional entrepreneurship - invites explicit examination of time and context as institutional entrepreneurs purposefully work towards changing existing or creating novel institutions in accord with interests they value. $^{2}$ Through the inclusion of original data and a historical case study of standardisation in the mature technological field of lightning protection, we explore the interplay of historical context with institutional work of creating, maintaining and disrupting institutions.

The specific institution examined is the lightning protection standard developed under the auspices of the National Fire Protection Association (NFPA) in the United States since 1904. Particular emphasis is placed on events post 1989 when manufacturers who had continuously supported the conventional standard (NFPA-780) sought to establish a competing standard in parallel (NFPA-781). When this failed, they sought to entirely remove the existing standard of almost 100 years. At the time of these events, historical precedent and tradition in lightning protection defined 'truth' and, through projections of the past into the future, what technologies might be right and possible. This empirical context affords an

unusual opportunity to explore how rhetorical history ${ }^{3}$ is deployed by 'challengers' seeking to disrupt the old or create a new standard over successive episodes of 'institutional work', and by 'custodians' engaged in maintaining the existing standard.

Several factors distinguish this case from existing studies of institutional entrepreneurship. First, while the majority of prior studies have been conducted in emerging fields characterised by high uncertainty ${ }^{4}$, we examine a mature field where the prevailing 
logics are supported by well-established dominant actors, making change more difficult. Second, few studies of failed institutional entrepreneurship exist, with cases typically selected on the dependent variable of successful change. ${ }^{5}$ In contrast, the inspiration for this study arose during interviews with participants as events unfolded in the 1990s, with uncertain outcomes. Our resultant emphasis on institutional work, rather than explaining success, helped us move beyond heroic conceptions of institutional entrepreneurship, recognise the discontinuous, non-linear processes that take place in institutional work, and identify 'unintended consequences' - an important concept that has been somewhat neglected in previous studies. ${ }^{6}$

This study shows how failure of institutional work may in fact lead to a strengthening and reproduction of existing institutions and their underlying logics, contrary to the institutional entrepreneurs' intent. It illustrates how rhetorical history can be deployed as a competitive resource that integrates the technical and symbolic realms, underscoring the potential value of history as an interpretive device for both challengers and custodians engaged in institutional work, and cautioning against its premature dismissal as merely 'the past'. The findings thus highlight the need for entrepreneurs to remain flexible and mindful in their institutional work ${ }^{7}$ such that the institutionalisation project may evolve ${ }^{8}$ with the mobilisation of needed support. ${ }^{9}$

\section{Standards, Institutions and Institutional Entrepreneurship}

A formal standard is a document that provides for common and repeated use, rules, guidelines or characteristics for activities or their results, established through recognised

standards development organisations existing at international, regional and national levels. ${ }^{10}$ A standard typically does one or more of four things: facilitates compatibility, requires a certain level of quality or safety, reduces the variation within a product range, or provides 
information. They thus reduce transaction costs, facilitate economies of scale, create network externalities, and reduce risks. Although standards are prepared for voluntary application, their use as the basis of regulations may render compliance mandatory. Similarly, when called up in contractual documents, incentives for conformity are strong even when there is no legal obligation. Standards are thus a powerful and pervasive, albeit often overlooked, underpinning of the business world. ${ }^{11}$

My conception of formal standards as institutions is couched in a critical realist perspective $^{12}$ as applied to institutional theory by Leca and Naccache. ${ }^{13}$ This perspective distinguishes between three domains in a stratified model of reality. The first domain is empirical reality, constituted by active agency or 'institutional work' by individual or collective actors aimed at creating, maintaining and disrupting institutions. ${ }^{14}$ The second level is that of institutions, humanly devised procedures that structure, enable and constrain political, economic and social interaction in a given technological field. ${ }^{15}$ A technological field represents a pattern of relationships among humans and the particular technologies (including beliefs, artefacts and evaluation routines) around which they coalesce, related to a particular product-market domain. ${ }^{16}$ Institutional logics - the socially constructed, historically situated shared beliefs, assumptions and material practices that guide decision making and behaviour ${ }^{17}$ - form the third level of reality. As Leca and Naccache succinctly observe: "While institutions are the rules of game, institutional logics are the underlying principles of the game."18

Formal standards - as documents specifying the rules of the game - are thus embedded in higher-order institutional logics that provide 'justification principles' by which actors can articulate and evaluate claims in the creation, maintenance and disruption of the standard over time. ${ }^{19}$ The development process is deliberative, governed by a highly prescribed set of rules and procedures. A fundamental principle informing the process is 'consensus', which involves a social process of negotiation and compromise, if not 
unanimity. The end result does not always reflect the best scientific solution to a technical issue, but is often an 'acceptable' scientific solution married to viable political, social, and economic realities. ${ }^{20}$ The process of consensus means that the resultant standard tends to mesh with broader belief systems and the daily life experiences of most who participate, and can become 'symbols of legitimacy'. ${ }^{21}$ Over time and through repeated use, the standard may become highly diffused and acquire a taken-for-granted quality, potentially infused with value beyond the technical requirements at hand. ${ }^{22}$ Formal standards have thus been criticised for impeding innovation and market entry of technologies that do not conform. These barriers provide an incentive for innovators to engage in diverse forms of institutional work to change existing or create new standards.

Early institutional theorists emphasised the enduring nature and taken-for-grantedness of institutions and their self-reproduction. ${ }^{23}$ Institutions are, however, the product of purposive action - intentional or otherwise. ${ }^{24}$ The relatively recent notion of 'institutional entrepreneurship' is an attempt to bring agency back into institutional theory. Institutional entrepreneurs are actors who, seeing an opportunity in particular institutional arrangements, mobilise resources to create new or change existing institutions to realise interests they value. $^{25}$ That is, they construct opportunities. ${ }^{26}$ Whether or not they are successful, institutional entrepreneurs attempt to somehow break with existing institutions. ${ }^{27}$ For success, they typically rely on the support of others and must therefore frame their institutional work in accord with the interests of potential allies. ${ }^{28}$ They thus share agency in the exploitation, and perhaps even identification, of opportunities for institutional change with other actors, ${ }^{29}$ and their ability to garner support is in part a function of their social position within a technological field. ${ }^{30}$ Powerful allies, such as legal bodies or governmental agencies, provide legitimacy to the institutional project. ${ }^{31}$ Diverse actors may become involved in interpreting new institutions, and competing logics and motivations may well exist even within a mature 
technological field. Institutional entrepreneurs thus need the ability to motivate the cooperation of others by providing them with common meanings and shared identities. ${ }^{32}$

From a critical realist perspective, institutional work is often highly context-specific and uncertain in outcomes. In a mature technological field, such as lightning protection with an established standard for over 90 years, historical context - or, more specifically, rhetorical history - inevitably plays a key role in the construction of meaning and persuasion, and the legitimation of competing technologies and standards. Rhetorical history treats history as a deliberate and strategic appropriation of the past in order to persuade: history is a resource intended to shape identity, motivate commitment, and frame action amongst key stakeholders, and integrates the technical and symbolic realms. ${ }^{33}$ Foster and colleagues have argued that by skilfully appropriating elements of collective memory - past events and historical images - managers can craft a narrative that creates cohesion and identification between the firm and external stakeholders with whom the appropriated memories resonate. They thus appropriate the legitimacy of broader socio-cultural institutions and generate 'social memory assets' or symbolic resources that confer legitimacy and competitive advantage. ${ }^{34}$ Our study illustrates the application of rhetorical history not just to craft narratives of firms, but as institutional work in the realm of lightning protection standards.

\section{Lightning Protection Standards}

Natural lightning is essentially an electrical spark, measuring in length greater than one kilometre. As shown in Figure 1a, lightning moves from cloud to ground in discrete, branching, luminous segments of approximately 50 metres in length. Each added length that the leader forges is called a step. Most commonly generated in summer thunderstorms and negatively charged, the 'stepped-leader' generally reaches between 5 and 10 kilometres. When the stepped-leader nears the ground, its relatively large negative charge induces 
concentrated positive charge on the conducting Earth beneath, especially on objects that project above Earth's surface. If the attraction between the opposite charges is strong enough, then the positive charge on the Earth will attempt to join and neutralise the negative charge above (Figure 1b). These self-propagating, upward electrical discharges are known as 'streamers'. If one of these streamers intercepts a branch of the downward moving steppedleader, the lightning strike point and path of electrical discharge between the cloud and ground is determined (Figure 1c).

\section{[INSERT FIGURE 1 ABOUT HERE]}

Conventional lightning protection systems for structures and buildings thus seek to provide preferred lightning 'attachment points' and 'paths' for the lightning current to follow from the attachment point into the ground without causing harm to the protected structure, contents therein, or services entering these buildings (e.g. electrical and telecommunication lines). These systems are typically composed of four elements: (1) 'air terminals' or 'lightning rods' at appropriate points on the structure to intercept the lightning; (2) 'down conductors' to carry the lightning current from the attachment point to the ground; (3) 'grounding electrodes' to pass the lightning current into the earth; and (4) over-voltage protection to protect equipment from surges and transients on incoming power, telecommunications and signal lines. ${ }^{35}$

The origins of lightning protection are attributed to Benjamin Franklin, whose earliest recorded suggestion of the lightning rod is May 1750. Lightning rods were first used for protective purposes around 1752 in France, with the first codification of a specific protected zone ascribed to lightning rods - that is, the region that is protected because lightning strikes the Franklin rod preferentially - emerging in 1823. In 1876 the application of the 'Faraday cage' principle (invented in 1836 by Michael Faraday) to lightning protection was proposed, whereby metallic conductors are criss-crossed and bonded together across a structure's roof and down the sides to create an electrostatic shield. In May 1878, the Royal Meteorological 
Society in Britain, the Royal Institute of British Architects, The Physical Society and the Society of Telegraph Engineers met in Bath to consider issuing a code of rules for the erection of lightning conductors. The Report of the Lightning Rod Conference was issued in 1882, and adopted by the British Lightning Committee formed in $1901 .^{36}$ In 1904, the first lightning protection standard in the U.S. - Specification for Protection of Buildings against Lightning - was published by the National Fire Protection Association (NFPA), and essentially adopted the recommendations from the 1882 report. Over time it was renamed NFPA-780 Lightning Protection Code. More than 27 editions of the NFPA-780 standard have been published since 1904 .

Effective lightning protection is particularly important with our growing reliance on sensitive electronics and computer equipment. NFPA-780 is thus widely adopted and used as a basis for safety regulation by government agencies and private organisations. The ability of manufacturers and installers to demonstrate compliance with NFPA-780 is an effective means of differentiation in a competitive marketplace, both in the U.S. and when exporting to countries where a dominant lightning protection standard is not yet established. ${ }^{37}$ As users become increasingly informed about their choices and insurance companies or regulators demand certification of an installation to the standard, conformance by manufacturers and installers becomes pivotal for market acceptance, and non-compliance can be used by competitors as a weapon to prevent market entry. This provides a powerful incentive for manufacturers of innovative technologies to attempt to shape the development of the standard.

Established in 1896, the NFPA develops, publishes, and disseminates more than 300 formal codes and standards intended to minimise the possibility and effects of fire and other risks. The formal standardisation process of the NFPA-780 is depicted in Figure 2. The Technical Committee serves as the primary consensus bodies responsible for developing and revising the standard, and ideally comprises balanced representation of insurance, regulators, 
consumers, users, installers/maintenance, manufacturers, special experts and testing laboratories. NFPA codes and standards are revised and updated every three to five years in Revision Cycles that begin twice each year. This starts with a call for proposals (i.e. a public notice asking for any interested party to submit specific written proposals on an existing document or a committee-approved new draft document), with numerous opportunities for debate and revision. It culminates in a decision by the Standards Council, based on all evidence and any appeals, whether or not to issue the document or to take other action. The process thus allows for the creation of new standards, their ongoing maintenance and change. The highly prescribed process of NPFA standardisation seeks to ensure that all potentially interested parties have voice.

\section{[INSERT FIGURE 2 ABOUT HERE]}

\section{Challengers to and Custodians of Conventional Lightning Protection Standards}

A major divide in lightning protection centres on the functioning of different air terminals intended to intercept or repel a downward stepped-leader and design methodologies for their placement and protective zones. Commercially available since the 1930s, Early Streamer Emission (ESE) terminals are claimed by their inventors and manufacturers to initiate upward streamers earlier and to produce longer upward streamers than is the case with conventional lightning rods. If effective, the streamer from the ESE terminal is more likely to intercept a downward stepped-leader ahead of competing streamers emanating from other objects, and hence offers an increased zone of protection. This would permit greater spacing between terminals and commensurately fewer terminals and conductors than in a comparable conventional system installed according to NFPA-780. Even with a premium price for the

ESE terminal, substantial cost savings accrue to the user. 'Custodians, 38 of NFPA-780 - that is, the dominant incumbents who have supported and defended the conventional methods of lightning protection using the Faraday cage and Franklin rods - generally refuted these 
claims of the ESE 'challengers'.

This divide in lightning protection standardisation exists, in part, because of the difficulty in establishing 'evaluation routines' ${ }^{39}$ - test methods for determining the effectiveness of a lightning rod. Failures in other components of lightning protection systems are relatively easy to characterise, ${ }^{40}$ and hence establishing widely accepted evaluation routines is somewhat straightforward. Scientific understanding of lightning's attachment to ground-based objects, however, remains incomplete and "the theoretical justification of the conventional approach is fairly crude." ${ }^{41}$ Large-scale phenomenon of a lightning strike cannot be replicated in a laboratory setting, and modern techniques to initiate lightning (e.g. rocket-triggered) may not produce identical results to the natural lightning phenomena. $^{42}$ The random nature of lightning means that collection and documentation of field experience is difficult, as is the generation of meaningful statistical data concerning the efficacy of different lightning rods. ${ }^{43}$ Thus, whereas Garud and Rappa found that once evaluation routines for a technology become widely accepted they develop the power to select out particular technological trajectories and result in the emergence of a dominant design, evaluation routines in relation to the air terminals remain contested. This absence of agreed evaluation routines foreshadows instability in the otherwise mature technological field of lightning protection, and opportunities to initiate change through innovation and institutional work.

\section{Method}

We examine the institutional work of custodians and challengers of NPFA-780 by examining their discourse and engagement with the highly prescribed process of standardisation. The analysis is based on original data sources comprising over 2000 pages and retained by the NFPA in the U.S. These include Standards Council Decisions (SCD) and Minutes (SCM); 
transcripts of hearings (TOH); Reports on Proposals (ROP) and Reports on Comments (ROC); written submissions of diverse stakeholders, such as letters, technical data, petitions and appeals; independent reports assessing claims of competing technologies; records of legal proceedings; and successive versions of the standard itself. These data capture the essential arguments used by the various actors, including the deployment of history as a competitive resource, as well as interim outcomes over successive episodes. They are supplemented by published historical accounts and interviews conducted in 1996 and 2010 with those involved in creating a competing standard (NFPA-781) and maintaining the existing standard (NFPA780).

\section{Episodes of Institutional Work}

Prior to 1989, the proponents of ESE terminals engaged in 'mild skirmishes' with the custodians of the conventional Faraday/Franklin system. These generally related to the scope of NFPA-780 and how ESE terminals were referenced within it. In 1989, however, the ESE manufacturers undertook substantive institutional work aimed at creating a new Standard (NFPA-781). This appears to be the first and only credible attempt to create a new Technical Committee for lightning protection in the history of the NFPA. The subsequent events unfolded across four discrete episodes from 1989 to 2002, summarised in Table 1. Below, we identify the justification principles deployed by the challengers and custodians, and describe key arguments and Standards Council decisions over successive episodes.

\section{[INSERT TABLE 1 ABOUT HERE]}

\section{Episode 1: Institutional Work of Creation (NFPA-781)}

On 24 April 1990, the Standards Council considered a request to establish a new project and Technical Committee for ESE lightning protection. The application was made on behalf of U.S. ESE manufacturers who supplied both Franklin/Faraday and ESE systems. Attending 
the hearing in support were ESE inventor/manufacturers, a representative of Gimelec (a French association of four electrical manufacturers of ESE and conventional systems) and an Australian inventor/manufacturer of ESE systems.

The justification principles of NFPA standardisation deployed by the challengers in support of proposed NFPA-781 are summarised in Table 2, along with illustrations. Particularly prominent were arguments of 'proven efficacy' of the ESE technology in the form of both scientific research and field or laboratory tests. Indeed, evidence of the efficacy of ESE systems was claimed to be at least equal, if not superior, to that available for the Franklin/Faraday system, despite the historical dominance of the latter. 'Procedural fairness' was also emphasised, particularly in the guise of ensuring equivalent burdens of proof were applied across the competing incumbent and challenger technologies and avoiding committee bias. This was coupled with concerns about the anticompetitive nature of a single NFPA standard for lightning protection: while the challengers were accused of seeking a standard to facilitate the marketing of their proprietary products, they retorted that the custodians of NFPS-780 were using the absence of an ESE standard as a marketing tool and a restraint of trade. These statements were made in the context of litigation initiated by an ESE manufacturer in which a number of proponents of the Franklin/Faraday technology were being sued for product disparagement, federal racketeering, and violation of the antitrust laws of the U.S. Custodians of NFPA-780 relied heavily on 'proven efficacy': creation of an installation standard for ESE terminals is, by implication, to validate the technology, and stressed it as "absolutely essential" that the committee require the validation of the technology itself by independent scientific inquiry.

[INSERT TABLE 2 ABOUT HERE]

The Council approved the formation of a new Technical Committee for ESE terminals and instructed the Committee to review available research and field experience to determine if a 
new standard is appropriate. It also voted to restrict the existing Lightning Protection Committee to systems using the Faraday cage/Franklin air terminals, and amended the scope of the existing committee accordingly. ${ }^{44}$ The Technical Committee on Lightning Protection Systems using Early Streamer Emission Air Terminals was thus formed in January 1991. The proposed NFPA-781, Standard for Lightning Protection Using Early Streamer Emission Air Terminals, was published for public review, followed by comment in the 1993 Fall Meeting Technical Committee Reports. Prior to the meeting, however, two proponents of conventional systems requested that the Council withdraw proposed NFPA-781 from the current revision cycle, invoking the same principles used by the challengers. Proven efficacy was sought in the form of independent scientific inquiry, as was 'fairness' in the form of a balanced Technical Committee not dominated by commercial ESE interests. This complaint was unsuccessful, and the draft standard was presented to the meeting in November 1993. The NFPA membership, however, voted to return the document to committee. Indeed, of the 17 NFPA members eligible to vote on the draft ESE standard, 16 voted to reject. Strong sentiments were expressed by manufacturers and design engineers of conventional systems concerning unproven efficacy, procedural fairness and harm. For example:

[This ESE document] may promote gypsyhood and seriously undermine standard practices... I am concerned that it will legitimate an unproven and possibly dangerous method of protection. ${ }^{45}$

Contrary to NFPA's own requirements for a non-biased committee... a majority of members are involved in manufacture and/or sale of early streamer emission terminals. ${ }^{46}$

Following that meeting, a petition was made by ESE proponents on 7 December 1993, requesting that the Council reject the vote of the NFPA membership and instead immediately issue proposed NFPA-781. A key part of their argument revolved around 'proven efficacy'. In particular, the proposed testing in NFPA-781 was argued to be far more comprehensive than any undertaken for conventional systems, and further independent verification of the 
ESE technology demanded by NFPA-780 custodians "should be done under the auspices of an adopted NFPA[781] standard." The second plank of their appeal was 'procedural fairness'. Specifically, it was argued that opponents of NFPA-781 had improperly influenced the Association members by means of "misrepresentation and false statements" that were "so prejudicial and inflammatory" that the proposed Standard NFPA-781 "cannot in the future get a fair hearing before the Association membership." ${ }^{\circ 7}$ Despite these arguments, the Council concluded that the "overwhelming vote" of the membership to return the document to committee showed that the consensus necessary to issue the document had not yet been achieved. ${ }^{48}$ The Council further concluded that this lack of consensus, "despite the sometimes contentious nature of the debate," derived from "genuine and legitimate questions on whether the early streamer emission technology has been adequately demonstrated to be effective." Nonetheless, the Council deferred ruling on the issuance of the standard in order to allow for an independent third party review of the scientific and empirical information available regarding ESE systems.

The independent third-party review requested by the Standards Council was provided by the National Institute of Standards and Technology (NIST), and became available in late April 1995. The Council convened a hearing on 18 July 1995 to consider the report and decided not to issue NFPA-781. In arriving at this conclusion, the Council noted the absence of reliable evidence that ESE terminals offer an increased zone of protection over that of conventional terminals. The NIST report did not invalidate the ESE concept, but concluded that it is "nearly impossible to make quantitatively meaningful statements or judgements about the performance of ESE devices in comparison to conventional Franklin rods" given the "sparsity of peer-reviewed literature". ${ }^{49}$ Further, while the Council noted that the NIST report called for more research, it concluded that "given the current state of knowledge, it does not appear that the type of further research and evaluation recommended by the NIST Report, which included comparative field tests, will be available in the short term."50 Hence, 
continuing standardisation activities for ESE systems would serve no useful purpose, and the ESE Technical Committee was discharged. ESE proponents were urged to petition the Council whenever they believed the technology had been "sufficiently validated to permit meaningful standards development.",51

\section{Episode 2: Institutional Work of Disruption (NFPA-780)}

The contents of the NIST report, while damaging to ESE ambitions, also inspired new institutional work by the challengers in the form of a direct attack on conventional Franklin/Faraday systems. Specifically, the NIST report observed:

There is still much that we do not understand about the behaviour of lightning, and the physics of lightning remains a topic of intense scientific investigation at research laboratories around the world... In fact, insufficient reliable data seem to exist about the performance of conventional rods... ${ }^{52}$

On 18 July 1995 the Standards Council considered a complaint by an ESE manufacturer requesting that NFPA-780, Lightning Protection Code, be withdrawn and no longer issued as an NFPA standard. ${ }^{53}$ This issue had earlier been raised on the floor of the May 1995 Annual Meeting of the NFPA and in advance of considerations concerning NFPA-781, but defeated. Attending the subsequent hearing and speaking in support of the complaint were manufacturers/inventors of ESE systems from Australia, France and the U.S. Those opposing the complaint were drawn from a wider stakeholder group, including a U.S. manufacturer of conventional systems, scientists in the U.S. (New Mexico Institute of Mining and Technology; New Mexico Tech.) and Brazil (University of Sao Paulo), and a user (British Columbia Hydro and Power Authority).

Challengers seeking to withdraw NFPA-780 again invoked the principle of "proven efficacy', arguing that irrefutable empirical or scientific evidence does not exist for conventional lightning protection methods. It was also argued that NFPA-780 was 
inadequate and inaccurate based on its coverage of the overall topic of lightning protection, and should thus be "downgraded" to a Standard, at best, and not be a Code. 'Fairness' was invoked: the Council should not issue NFPA-780 having declined to issue proposed NFPA781 when the NIST report clearly signalled deficiencies in 'proven efficacy' for both technologies. That said, it appeared to the Council that all but one of the ESE manufacturers wished NFPA-780 to be withdrawn only in the event that the proposed NFPA-781 was not issued. Disruption to NFPA-780 was not, in and of itself, the primary goal, but a tactic to secure NFPA-781.

Custodians opposing withdrawal of NFPA-780 drew on the fundamental principle of consensus within the NFPA standards making process as a source of legitimacy: since 1904, NFPA-780 had been reinstated through numerous editions using the fundamentally same consensus process. There was strong historical precedent for its continuation. Also invoking the principle of 'proven efficacy' in relation to the conventional technology, they argued that the current NFPA-780 is based on sound theory and historical experience that had served well for many decades. As observed by the Standards Council, "both sides of the argument sought, to some extent, to draw support from the conclusions of the NIST report."

After weighing all submissions, the Council voted to deny the complaint and issue NFPA-780, observing that there was no justification to overturn the strong consensus supporting NFPA-780. Further, the purpose of the NIST report was not to evaluate conventional systems. It was deemed that there was no basis in that report, or any other information presented, for the Council to conclude that conventional terminals were ineffective or current installation requirements inadequate, and hence no basis for withdrawing the Code for conventional systems. This did not preclude the possibility of improvements in NFPA-780. 
The ESE proponents' institutional work of disrupting NFPA-780 did, however, result in small gains. Specifically, NFPA-780 was renamed an installation standard, rather than a Code. As explained by an Australian ESE manufacturer in 1997:

The [ESE manufacturers] tried to get a second set of standards going in the U.S., but that fell in a heap. But it fell in a heap in such a way that their normal standards were then questioned and downgraded because they didn't have the technical data to back up their own [conventional] standard. ${ }^{55}$

Also, since ESE technology was deemed beyond the scope of the Technical Committee who developed NFPA-780, the Council decided to expressly exclude coverage of ESE systems from the standard. On the one hand, ESE proponents could now argue that the NFPA-780 standard is irrelevant to their technology, and draw on ESE type standards of other countries for legitimacy. On the other hand, they still had no independent standard in their home market. Clearly dissatisfied, proponents of ESE systems appealed the decision of the Standards Council, but again failed. ${ }^{56}$

\section{Episode 3: Work of Institutional Creation Re-visited}

Three years later, in 1998, the principal ESE proponents requested that the Standards Council reopen the proceedings for issuing a standard for ESE systems, and conduct a de novo review, reweighing and considering all evidence anew, including evidence not previously available. This would, in part, fulfil a settlement agreement and resolve litigation by an ESE proponent against the NFPA and its 'co-conspirators' accused in December 1996 of having conspired to unreasonably restrain trade in the market for lightning protection systems in the U.S. by engaging in a wrongful course of conduct designed to prevent issuance of the proposed NFPA-781. ${ }^{57}$ Via this coercive Settlement Agreement, the ESE manufacturers again sought the creation of a standard for ESE systems that would be "separate and distinct from NFPA-780." 58 
Granting the request on 8 October 1998, the Council authorised the creation of an independent panel to determine (1) whether the ESE lightning protection technology is scientifically and technically sound; and (2) whether it is supported by adequate scientific theoretical basis and laboratory testing. The resultant 'Bryan Report' was received by the Council on 30 September 1999. It was made available for public comment, with a hearing held on 27 April 2000 to consider the Report and related requests.

The Bryan Report concluded that while there does appear to be an adequate theoretical basis for the ESE terminal concept and design from a physical point of view, there does not appear to be an adequate theoretical basis for the claim of enhanced areas of protection with limited down conductors and grounding systems. ${ }^{59}$ Further, while high voltage laboratory tests were thought to be adequate in scope and quantity, they were not considered equivalent to an evaluation of the complete ESE system under natural thunderstorm conditions. However, in what was becoming a common theme, the report further went on to point out that "the recommended [NFPA-780] lightning protection system has never been scientifically or technically validated and the Franklin rod air terminals have not been validated in field tests under storm conditions."60 The Bryan Panel also recommended, unsolicited by the Standards Council, that the current NFPA-780 Technical Committee be discharged and newly formed with additional membership across all categories except manufacturer (implying bias in current membership), and that the NFPA-780 document be reformulated as a Recommended Practice or Guide in light of the lack of 'proven efficacy'. Again, both sides drew on the report to support their views.

Despite reviewing the issue anew, the Council came to similar conclusions as in July 1995 and on 28 April 2000 decided not to issue a standard for ESE systems and to cease standards development activities in this area. ${ }^{61}$ It observed that the proposed standard on ESE systems had never achieved consensus within the NFPA. Immediate issuance of a proposed standard under those circumstances would be unprecedented, albeit not impossible. 
The additional questions raised by the Bryan panel concerning NFPA-780 were, however, in keeping with its authority to address "any other issues it deems relevant." With NFPA-780 currently completing a revision cycle and the new edition to be presented and debated at the May 2000 Technical Session, the Council delayed action on these questions, but implicitly invited institutional disruption:

If, for example, there is a motion to return NFPA-780 to committee which raises issues concerning the validity of the document (as was done in 1995...) or which questions the appropriateness of designating the document as a Standard, as opposed to a Guide or Recommended Practice, the debate that follows such a motion would be helpful to the Council in considering any further appeals concerning NFPA-780...

The proponents of ESE terminals accepted this invitation.

\section{Episode 4: Work of Institutional Disruption Re-visited}

A motion to return the proposed 2000 edition of NFPA-780 to the Technical Committee was made at the May 2000 Technical Session. Defeat during the floor debate constituted a recommendation to issue the new edition of NFPA-780 and retain it as a Standard. A subsequent appeal to the Standards Council was made by a private individual and an ESE manufacturer. While the Council rejected the request to reinstate the ESE project, the ESE entrepreneurs' institutional work of disruption appeared more successful.

The main obligation of the Council in relation to the issuance of standards is to determine whether a consensus of relevant interest has been achieved. Precedent exists for the rejection of consensus recommendations where substantive technical questions have been raised related to the basis of the recommendation. The Bryan Report raised such concerns in relation to NFPA-780 and, at the hearing of 18 July 2000, Dr Bryan went beyond the initially suggested reformulation of the standard as a guide or recommended practice to express the authors' sentiments for a complete withdrawal of NFPA-780. He stressed: 
We couldn't see that [NFPA-780] met the requirements... for a standard because of the lack of verification of the entire concept of the system as being scientifically verifiable or even effective under natural lightning conditions, any more than ESE or any other system." 62

Viewed as "respected and neutral observers", these opinions, while not treated as definitive, were not ignored. ${ }^{63}$ Further, the earlier NIST report had made similar observations. While the custodians' defence of NFPA-780 was considered "vigorous", absent was a systematic review and analysis of the technical basis for NFPA-780. Historical precedent was no longer sufficient. In an even more dramatic turn, the Council announced its intent to withdraw the 1997 edition and terminate the Lightning Protection project, and directed a notice of this intent be published and comment solicited.

This palpable threat to a long-standing institution mobilised a wide array of 'high status' stakeholders that confer legitimacy ${ }^{64}$ to an extent not evident in earlier challenges. Submissions in support of NFPA-780 were made from "sophisticated government and other users", including members of the United States Army, the United States Navy, the United States Department of Energy, and the National Aeronautics and Space Administration, among others. In an approach it explained as "most consistent with the deference and respect that the Council must give the consensus process that has developed and strongly supported the successive editions of NFPA-780", the Council deferred action to allow proponents time to submit substantiation in support of NFPA-780. This was to include an "independent" literature review and analysis from a "reliable source" demonstrating the "validity of the basic technology and science underlying traditional lightning protection systems." ${ }^{, 65}$

Two particularly key reports were submitted: one authored by senior scientists and engineers employed across federal government agencies (Federal Interagency User Group Report) that provided a detailed literature review of the development of lightning protection, 
including field data; and a report of the Committee on Atmospheric and Space Electricity of the American Geophysical Union. Claims of bias and lack of independence in writing the reports, procedural inadequacies, questionable science and evidence - arguments that had been used by both parties in previous episodes of institutional work - were again evident. The opposition of the principal ESE proponent was to a large extent discredited, however, by the argument that NFPA-780 should only continue if NFPA-781 is also issued. It became apparent that what was at issue in the appeal was not so much the validity of conventional lightning protection, but the asserted validity of ESE systems. Indeed, as the Standards Council observed, a representative of this ESE manufacturer had voted in favour of each new edition of NFPA-780 in recent history, including the then most recent 2000 edition. ${ }^{66}$ Overall, the Council considered the reports, along with additional submissions, to meet the requirements of independence, reliability and validation of the conventional technology.

What sets this period apart from earlier episodes is the involvement of diverse stakeholders in the institutional work countering disruption to NFPA-780. In addition to abovementioned government agencies, this included scientists (e.g. from New Mexico Tech's Langmuir Laboratory for Atmospheric Research), office bearers of international associations (e.g. Scientific Committee of the International Conference on Lightning Protection), members of the U.S. Congress and Florida State House of Representatives, installers and manufacturers - including some who had previously supported efforts to establish the proposed NFPA-781. One such manufacturer now sought not only the continuation of NFPA-780 but also its reinstatement as a Code:

The NFPA-780 standard is highly regarded and has served the USA and international lightning protection community well over the decades. The issue of its continuance is unquestionable...The importance of the NFPA in providing strong leadership in the industry cannot be underestimated. ${ }^{67}$

Consistent with a greater involvement of stakeholders from user groups was the heightened 
use of the principle of 'harm mitigation' by proponents of NFPA-780, with this apparent need for reassurance at times overshadowing debates of technical merit. Further, no longer was discussion limited to abstract notions of 'the public', 'users' or 'consumers': "[T]o discontinue this standard or its technical [committee] would be a disservice to the nation."

In a decision of 4 October 2001, the Council voted to continue the existing project on lightning protection and to issue NFPA-780, Standard for the Installation of Lightning Protection Systems. It is currently in the 2011 edition, and remains the sole standard for lightning protection of the NFPA.

\section{Discussion}

The failure of the institutional entrepreneurs in their repeated attempts to establish a new NFPA-781 standard or disrupt the existing NFPA-780 held unintended consequences. First was a strengthening of NFPA-780 itself. The institutional entrepreneurs' attempts to entirely remove NFPA-780 ultimately led to a more comprehensive understanding of the scientific and empirical origins of the standard, thereby strengthening its legitimacy. This compilation of evidence was only possible with the mobilisation of diverse stakeholders, at home and abroad, with sufficient resources and interests. Ironically, the actions of the U.S. ESE manufacturers facilitated this mobilisation. When the institutional project focused only on the creation of a sub-field in lightning protection, coalescing around an additional standard NFPA-781 while leaving NFPA-780 intact, they were able to garner the support of other ESE manufacturers around the world. The re-framing of their institutional project as a direct attack on the very existence of NFPA-780 was not, however, in the interests of most of these allies - many of whom also manufactured or installed conventional systems for lightning protection. 
Second was a strengthening of the consensus logic. While the principle of consensus was referenced in all Standards Council and NFPA board of directors' decisions, the final decision to continue the lightning protection project and issue the 2000 edition of NFPA-780 included language of reverence: the consensus process was owed "deference" and "respect". Further, the decisions pertaining to the rejection of NFPA-781 were referenced as authoritative precedent when assessing other unconventional technologies - even where prior precedents pertaining to that very technology existed. The council required "ample basis in scientific and technical literature" shown by an "independent review and reliable source." 69 Strengthening the emphasis on justification through science, empirical evidence and consensus was not, in the short term at least, in the ESE innovators' interests.

Legitimating the proposed NFPA-781 required the institutional entrepreneurs to demonstrate adherence to the institutional logic of standardisation or displace those logics and establish new legitimacy criteria. Consensus as a justification principle was never directly questioned, although its enactment (e.g. through committee bias) received criticism from all sides. Yet, the mechanism of determining consensus was a ballot that would, almost inevitably, favour the incumbent actors. While the Standards Council could overturn a consensus decision, the basis for doing so was limited. Small gains in a consensus process with dominant incumbents in mature fields may be harder to achieve than in more fragmented emerging fields, and greater value should thus be placed upon incremental achievements. This observation stands in marked contrast to institutional work in episode 1, where the ESE entrepreneurs rejected the vote to return the draft NFPA-781 to committee for further work and initiated a more direct attack on NFPA-780. Successful institutional work may entail drawing careful boundaries around, and prescribing limits to, the scope of the institutional project itself so that incremental gains are not undone.

While the criterion for legitimacy was encoded in the institutional logics deployed similarly by incumbents and challengers, these outcomes were not inevitable. The highly 
prescribed consensus process of standardisation, described in Figure 2, emphasises iterative public debate. The meanings attached to scientific reports, empirical evidence and test methods and how they adhered to the institutional logics of standardisation over successive episodes of institutional work were not neutral and self-evident, but highly contested. Hence, persuasive language was an important tool for both incumbents and institutional entrepreneurs. Both the custodians of and challengers to NFPA-780 deployed history as a competitive resource in their institutional work of creating NFPA-781, or maintaining or disrupting NFPA-780. How they deployed history varied across groups and successive episodes.

The custodians of NFPA-780 deployed history as a technical resource - incorporating 'facts' about the technology's utility, performance and physical application - in all four episodes, with particular emphasis on historical precedent. Rhetorical history invoking precedent is often used to counteract radical change, and promote path-dependent, incremental change. ${ }^{70}$ Legitimacy was fostered through reference to the accumulation of empirical evidence and scientific knowledge over time, linking these to webs of causality that identified some methodologies as science and others as mere 'quackery'. Path dependent, incremental change is presented as more rational and trustworthy. As expressed by the Department of Army user representative: “There's been over 200 years of empirical observation to justify writing the Standards on the Franklin/Faraday systems". ${ }^{71}$ A history of meeting the needs of the standard's most immediate stakeholders also fostered legitimacy, as explained by one manufacturer in May 1995: "There are any number of major agencies and users out there that have relied for years and would like to continue to rely for years on this document being a standard". ${ }^{72}$

The class of standard to which NFPA-780 belonged - a standard established through highly prescribed consensus procedures - meant that the standard became a repository for public confidence in the procedures and technologies it described. As proclaimed by an 
installer of conventional systems in April 2000: “[T]o throw out a document that has a 100year history, or close to a 100-year history is very impudent." ${ }^{, 73}$ Further, a challenge to NFPA-780 was also a challenge to a network of related standards and essential institutions, as another installer explained in May 1995: "To say there is no scientific evidence about [NFPA-780] is to accept there is no science behind any other NFPA document or documents... [It] is to accept that a large chunk of the National Electrical Code is similarly meritless."74 This application of historical rhetoric by the incumbents defending NFPA-780 involved a degree of mythologising - a form of institutional work that aims to preserve the normative underpinnings of an institution by creating and sustaining myths regarding its history. ${ }^{75}$ In episode 4, for example, the standard was depicted in a report by Federal users of NFPA-780 as largely uncontested and consistent over time: "[Anderson 1880] ${ }^{76}$ is essentially the first lightning protection standard. Even today, we follow most of the recommendations of this book." ${ }^{, 77}$ At the same time, successive adaptations were acknowledged by both the Federal users and a report from scientists supporting conventional systems in June 2001: "Many updates to the original NFPA lightning protection standard of 1904 have been made to incorporate new scientific findings. ${ }^{, 78}$ Historical precedent thus carried the past forward through time, preserving both the invariant core content and successive interpretations and adaptations of the past. ${ }^{79}$

The strategic deployment of history as a symbolic resource by custodians of NFPA780 emerged as they tried to counter a challenge to NFPA-780 in episode 2, and gained momentum in episode 4 when faced with more palpable threat to NFPA-780's existence. Whereas legitimation based on history as a technical resource relied on discursive evaluation and public debate of the technical merits of and consequences associated with competing standards, history as a symbolic resource implicates unspoken orienting assumptions. It thus draws on more deeply rooted cognitive dimensions of legitimacy based on taken-forgrantedness and comprehensibility. ${ }^{80}$ By drawing parallels with other enduring, high-status 
institutions such as the National Electrical Code and judiciary, NFPA-780 custodians fostered this taken-for-grantedness: "The other thing is, maybe this [Bryan report panel] didn't give a lot of credence to historic precedence, but you have to consider what the court and the legal system in this country does. And they give a lot of credence to historic precedent" (Installer, April 2000). ${ }^{81}$ Similarly, linking current activities to predecessors and eminent historical figures is a form of institutional work that offers a sense of continuity between past and future behaviours. ${ }^{82}$ This rhetoric was strengthened as custodians narrated the lineage of NFPA780, emphasising the 'forgotten history' as a defence in episode 4. As the Department of Army user representative proclaimed in October 2001:

\footnotetext{
"[W]e stand in a similar situation to our predecessors in 1882, where a general meeting of lightning protection experts was convened, consensus was achieved and ultimately resulted in NFPA-780; into the early 1900s, as early as the 1930s, utility and effectiveness of lightning protection was settled and sources relegated to obscurity until again resurfaced today, as embodied in our report. Let us not reverse over 100 years of scientific development. Let us not repeat the error of letting critical data, once again, pass into obscurity." 83
}

Recent scientific developments and empirical evidence for conventional systems were framed by historical records showing the origins, efficacy and incremental improvements in Franklin rods from as early as 1766, even quoting Franklin directly. Franklin is not only recognised for his discoveries and theories regarding electricity and the lightning rod, but also as politician, scientist, diplomat, entrepreneur and 'Founding Father', influential in inventing the type of society the U.S. would become. ${ }^{84}$ The custodians thus simultaneously deployed history as both a technical and symbolic resource, and related the history of NFPA-780 to nationalistic sentiment. The skilful appropriation of Benjamin Franklin, predecessors, the National Electrical Code and other high-status institutions such as the judiciary as social memory assets situated NFPA-780 within a wider symbolic framework considered to be external and objective. That is, cognitive legitimacy was reinforced by co-identifying the 
history of NFPA-780 with the values and institutions of the broader community in which it was embedded. ${ }^{85}$

In contrast, the challengers failed to effectively deploy rhetorical history in their institutional work of creation or disruption, in part due to their late-mover position. Claims of precedent, for example, were necessarily limited in scale, as captured by the representative of a U.S. ESE manufacturer in April 1990: "This product has been in the field since 1932. It has a track record which is equal, if not superior, to the Faraday system" ${ }^{86}$ Most ESE proponents, however, endeavoured to differentiate their product from those of the past. Early ESE-type products tended to contain radioactive isotopes. Not only had this technology been largely discredited by the scientific community but the, then, recent accident at the Chernobyl nuclear power plant in April 1986 connected radioactive lightning rods with collective memories of disaster likened to 'biblical calamity'. ${ }^{87}$ Rhetorical history was thus used less to build the legitimacy of NFPA-781 directly, and more in an attempt to undermine NFPA-780. In May 1995, for example, an ESE proponent observed:
"I suspect most of you here do not realise that the lightning protection standard is as old as it is. The concept is somewhere around 250 years old. Truth is, the concept has not changed significantly in those 250 years. My question for all of you here is why are we using a 250 year old concept to protect [con]temporary equipment?" 88

Similarly, while the heritage of Benjamin Franklin in lightning protection was referenced, it was not in an effort to appropriate and connect the proposed NFPA-781 with cultural and historic values, but to discredit. As one ESE manufacturer asserted in July 1995:

\footnotetext{
"The Ben Franklin defence of the code will no longer suffice. We cannot legitimately point out that Ben Franklin developed this principle over 220 years ago and that it has stood the test of time." 89
}

Undermining core assumptions and beliefs is a tactic of disruption designed to decrease the 
perceived risks of innovation and differentiation. ${ }^{90}$ By discrediting history so sweepingly, however, the institutional entrepreneurs foreclosed an opportunity to deploy rhetorical history more strategically.

Does this mean that history as a symbolic and technical resource is available only to incumbents in mature technological fields absent of agreed evaluation routines and denied to institutional entrepreneurs seeking to bring about change? A more nuanced history of lightning protection suggests otherwise. In episodes 1 and 3 of institutional creation, deploying history as a symbolic resource was a device by which challengers might have better manipulated the degree of certainty implied by the conventional systems and constructed their own innovation in a manner more consistent with broader myths or cultural accounts. Franklin had refused to patent the lightning rod or otherwise profit from the invention. As proclaimed by Anderson in 1880, "Never before, was a grand idea thrown out to all the world with more munificence of spirit." 91 The diffusion of Franklin's technology was not, however, smooth "even in the Northern States of America, though inhabited by a highly intelligent race, there were great difficulties to be overcome." Significant opposition came from ministers of religion who thought the iron rods not entirely free from the "suspicion of infidelity". The priests in Roman Catholic countries of Europe "craftily attached to them a stinging name, calling them heretical rods," with mobs tearing down the Franklin rods as they were erected. Early on, the invention was "looked coldly upon by the public and critics" in England by virtue of "not appearing under the patronage of the Royal Society, the supposed fountain-head of all legitimate science.” In France, early scientific opposition was attributed to the "wounded vanity" of an esteemed scientist who "used all his influence among the public, in the scientific world, and at the French court...to deprecate Franklin's lightning conductors."

Rather than explicitly discrediting NFPA-780 - a difficult endeavour given the high levels of legitimacy it enjoyed - an opportunity existed for the skilful appropriation of 
Benjamin Franklin as a social memory asset to create a narrative favouring radical invention, entrepreneurship and perseverance in the face of unjust, prejudiced government, religious and scientific authorities. This institutional work of rhetorical history would involve changing normative associations ${ }^{92}$ - re-making the connections between the established lightning protection practices and the moral and cultural foundations for those practices. If used by the challengers in early episodes, before the foreclosure of opportunities for historical reinterpretation as a competitive resource, such institutional work could serve to shift the framing of the ESE technologies away from stakeholders asking Why would we adopt into this or any standard technology that challenges 100 years - even 250 years - of historical precedent? to one of What interests have conspired for so long and continue to conspire to prevent the inclusion of ESE innovations within the NFPA standards for lightning protection $?^{93}$

\section{Concluding Remarks}

As with lightning itself, the institutional work of challengers and custodians unfolded in discrete steps, guided by a highly prescribed standardisation process and logics, but nonetheless branching in indeterminate directions. The emphasis to date on success, rather than failure, introduces a strong bias in our understanding of institutional entrepreneurship, creating a general image of typically heroic and successful action in regards to achieving intended effects. ${ }^{94}$ In contrast, our study portrays institutional entrepreneurship as a collective, at times discontinuous, ongoing and uncertain accomplishment, unfolding over successive episodes of interaction..$^{95}$

Our research highlights the interplay of historical context and processes of institutional entrepreneurship. In particular, it extends existing sensitivity towards how rhetorical history may be deployed as a competitive resource beyond the firm to the domain 
of institutions. ${ }^{96}$ While uncertainty surrounding the attachment process of lightning to ground objects and related evaluation routines foreshadowed instability in the otherwise mature field and opportunities to initiate change, it also denied both challengers and custodians an important potential source of legitimacy. Custodians of conventional lightning protection initially invoked historical precedent as a technical resource in their institutional work of maintaining NFPA-780. Faced later with a credible attack on the very existence of NFPA-780, they skilfully appropriated collective memory, deploying history as a symbolic resource to gain advantage. In contrast, the analysis suggests that rather than undermining historical precedent and foreclosing opportunities for subsequent strategic deployment of history as an interpretive device, the challengers may have been better served by deploying history as a symbolic resource early in their institutional work to mobilise support or, at the very least, diffuse potential opposition. The proposition that emerges is that challengers seeking to disrupt existing or create new institutions in a mature technological field with powerful custodians need to deploy symbolic resources that build cultural-cognitive legitimacy earlier in their institutional work than the dominant incumbents working to maintain the existing institutions, or challengers in more fragmented, emerging fields.

Further research could thus usefully explore how history can be deployed to frame an institutional project as consistent with the interests of potential allies; the sequencing of historical rhetoric according to entrepreneurial intent and the nature of organisation and stability in the field ${ }^{97}$; and the form and sustainability of the legitimacy ${ }^{98}$ acquired through use of history as a technical or symbolic resource. As this study shows, formal standardisation forums are potentially rich contexts of social and economic importance in which to explore such dynamics. The highly prescribed consensus process generates a repository of documents through which diverse forms of the institutional work, effects on the relevant standard, and the causal power of underlying logics - that is, all three levels of 
reality - can be discerned, presenting valuable opportunities for generating further insight into the interplay between historical context and entrepreneurial process.

\section{Acknowledgements}

This paper has benefitted greatly from the insightful comments and guidance of the Special issue reviewers and editors. I am also appreciative of comments received from John Sillince, Mercedes Delgardo and seminar participants at the Fox Business School where much of this research was undertaken as a visiting research scholar; of Mary Maynard and Sue Marsh of the NFPA; and of the generosity of those who shared their first-hand experiences. 


\section{Bibliography}

Anderson, R. Lightning Conductors - Their History, Nature and Mode of Application. London, E. \& F. N. Spohn, 1880.

Barley, S. R. and P. S. Tolbert. "Institutionalization and structuration: Studying the links between action and institution”. Organizational Studies 18, 1 (1997): 93-117.

Battilana, J. "Agency and institutions: The enabling role of individuals' social position". Organization 13, 5 (2006): 653-676.

Battilana, J., Leca, B. And E. Boxenbaum. "How actors change institutions: Towards a theory of institutional entrepreneurship". The Academy of Management Annals (2009): 65107

Bhaskar, R. A Realist Theory of Science. 2nd edn. Brighton: Harvester-Wheatsheaf, 1978.

Bryan, J.L., R.G. Biermann, and A.Erickson. "Report of the Third-Party Independent Evaluation Panel on the Early Streamer Emission Lightning Protection Technology.” (Submitted to the National Fire Protection Association Standards Council, 1 September. 1999).

Dacin, M.T. and A.C. Dacin. "Traditions as institutionalized practice: implications for deinstitutionalization." In Handbook of organizational institutionalism R. Greenwood, C. Oliver, R. Suddaby and K. Sahlin-Andersson, 327-351. Sage, 2008.

DiMaggio, P. "Interest and agency in institutional theory." In Institutional Patterns and Organisations. Culture and Environment, ed. L.G. Zucker, 3-21. Cambridge, Massachusetts: Ballinger Publishing Company, 1988.

DiMaggio, P. J. and W.W. Powell. "Introduction." In The New Institutionalism in Organizational Analysis, eds. W.W. Powell and P. J. DiMaggio, 1-38. Chicago, IL: University of Chicago Press, 1991.

Federal Interagency Lightning Protection User Group. "The Basis of Conventional Lightning Protection Technology. A Review of the Scientific Development of Conventional Lightning Protection Technologies and Standards.” (June 2001).

Fligstein, N. "Social skill and institutional theory". American Behavioural Scientist 40, 4, (1997): 397-405.

Foster, W. M., R. Suddaby, A. Minkus, and E. Wiebe. "History as Social Memory Assets: The example of Tim Hortons." Management and Organizational History 6, 1 (2011): 101-120. 
Greenwood, R. And P. Suddaby. "Institutional entrepreneurship in mature fields: The big five accounting firms.” Academy of Management Journal 49 (2002): 27-48.

Garud, R., V. Hardy, and S. Maguire. "Institutional entrepreneurship as embedded agency: An introduction to the special issue." Organisation Studies 28 (2007): 957-69.

Garud, R., S. Jain, and A. Kumaraswamy. "Institutional entrepreneurship in the sponsorship of common technological standards: The case of Sun Microsystems and Java." Academy of Management Journal, 45 (2002): 196-214.

Garud, J. And M.A. Rappa. "A socio-cognitive model of technology evolution: The case of cochlear implants." Organisation Science 5, 3 (1994): 344-62.

Greenwood, R. and R. Suddaby. "Institutional entrepreneurship in mature fields: the big five accounting firms." Academy of Management Review 49, 1 (2006): 27-48.

Greenwood, R., R. Suddaby, and C.R. Hinings. "Theorizing change: The role of professional associations in the transformation of institutionalized fields." Academy of Management Journal, 45, (2002): 58-80.

Hibbert, P. and C. Huxham. "The past in play: Tradition and modularity in the structures of collaboration." Organization Studies, 31, 5 (2010): 525-554.

Isaacson, W. Benjamin Franklin: An American Life. New York: Simon \& Schuster, 2003.

Jepperson, R.L. "Institutions, institutional effects and institutionalism". In The New Institutionalism in Organizational Analysis, eds. W.W. Powell and P.J. DiMaggio, 143-63. Chicago, IL: University of Chicago Press, 1991.

Leca, B. And P. Naccache. "A critical realist Approach to institutional entrepreneurship." Organization, 13 (2006): 627-651.

Lawrence, T. B. and R. Suddaby. "Institutions and institutional work." In Handbook of Organizations Studies, 2nd edn. Eds. S. R. Clegg, C. Hardy, T. B. Lawrence and W. R. Nord, 215-254. Thousand Oaks, CA: Sage, 2006.

Lawrence, T.B., R. Suddaby, R. And B. Leca. Institutional Work: Actors and agency in institutional studies of organization. Cambridge: Cambridge University Press, 2009.

Macguire, S., C. Hardy, and T.B. Lawrence. "Institutional entrepreneurship in emerging fields: HIV/AIDS treatment advocacy in Canada." Academy of Management Journal 47 (2004): 657-79.

McGaughey, S.L. Narratives of Internationalisation. Standards, Legitimacy and Portfolio Entrepreneurs. Cheltenham: Edward Elgar, 2007. 
Montiel, I. B.W. Husted. "The adoption of voluntary environmental management programs in Mexico: First movers as institutional entrepreneurs." Journal of Business Ethics 88 (2009): 349-63.

Oliver, C. “Antecedents of deinstitutionalisation.” Organisation Studies 13, 4 (1992): 563588.

Popp, A. and R. Holt, “The presence of entrepreneurial opportunity”, Business History (2012) forthcoming.

Report of the Committee on Atmospheric and Space Electricity of the American Geophysical Union on the Scientific Basis for Traditional Lightning Protection Systems, (June 2001).

Roscoe, P., A. Discua Cruz and C. Howorth, "How does an old firm learn new tricks? A material Account of Entrepreneurial Opportunity". Business History (2012) forthcoming.

Scott, W.R. Institutions and Organisations. third edn. London: Sage Publications, 2008.

Sine, W.D. and David, R.J. eds. Institutions and Entrepreneurship. Research in the Sociology of Work (Vol. 21). Emerald Group Publishing Limited, 2010.

Suchman, M.C. "Managing legitimacy: Strategic and institutional approaches." Academy of Management Review 20, 3 (1995): 571-610.

Suddaby, R., W.M. Foster, and C. Quinn-Trank. "Rhetorical history as a source of competitive advantage." In Advances in Strategic Management: The Globalization of Strategy Research (Vol. 27, pp. 147-173) eds. J. Baum and J. Lampel. Emerald Group Publishing Limited, 2010.

Suddaby, R, and R. Greenwood. "Rhetorical strategies of legitimacy". Administrative Science Quarterly 50 (2005): 35-67.

Thornton, P.H. and W. Ocasio. "Institutional logics", in R. Greenwood, C. Oliver, S. Kerston Andersen, \& R. Suddaby (eds.) Handbook of organizational institutionalism, CA: Sage, 2008.

Tobias, J.M. "The basis of conventional lightning protection systems." IEEE Transactions of Industry Applications 40 (2004): 958-62.

Uman, M.A. The art and science of lightning protection. Cambridge: Cambridge University Press, 2008.

Uman, M.A. and V.A. Rakov. "A critical review of non-conventional approaches to lightning protection.” American Meteorological Society December (2002): 1809-1820. 
Van Brunt, R.., T.L. Nelson, and S.L. Firebaugh. "Early Streamer Emission Air Terminals Lightning Protection Systems: Literature Review and Technical Analysis” (NIST Report), (National Fire Protection Research Foundation, April 1995).

Velkar, A. "Transactions, standardisation and competition: Establishing uniform sizes in the British wire industry c.1880.” Business History 51, 2 (2009): 222-247.

Zipse, D.W. Lightning protection systems: Advantages and disadvantages. IEEE Transactions on Industry Applications, 30, 5 (1994): 1351-1361. 
Figure 1: Lightning formation and conventional protection

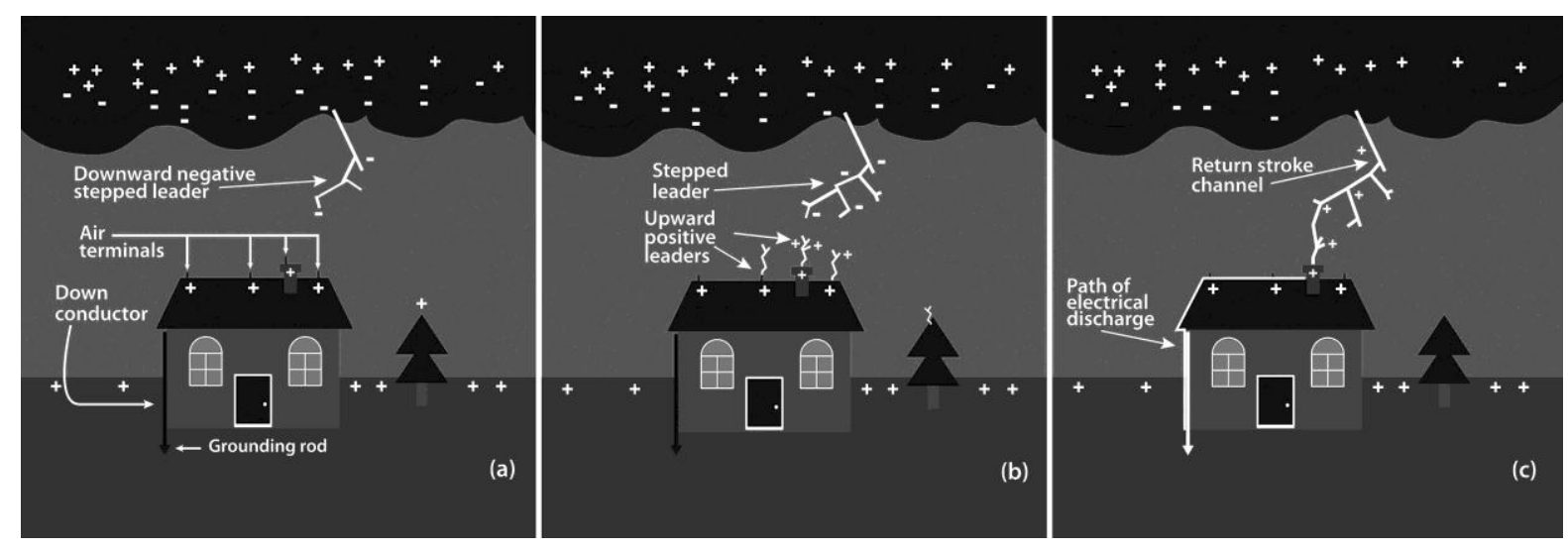


Figure 2: NFPA Standards Development Process

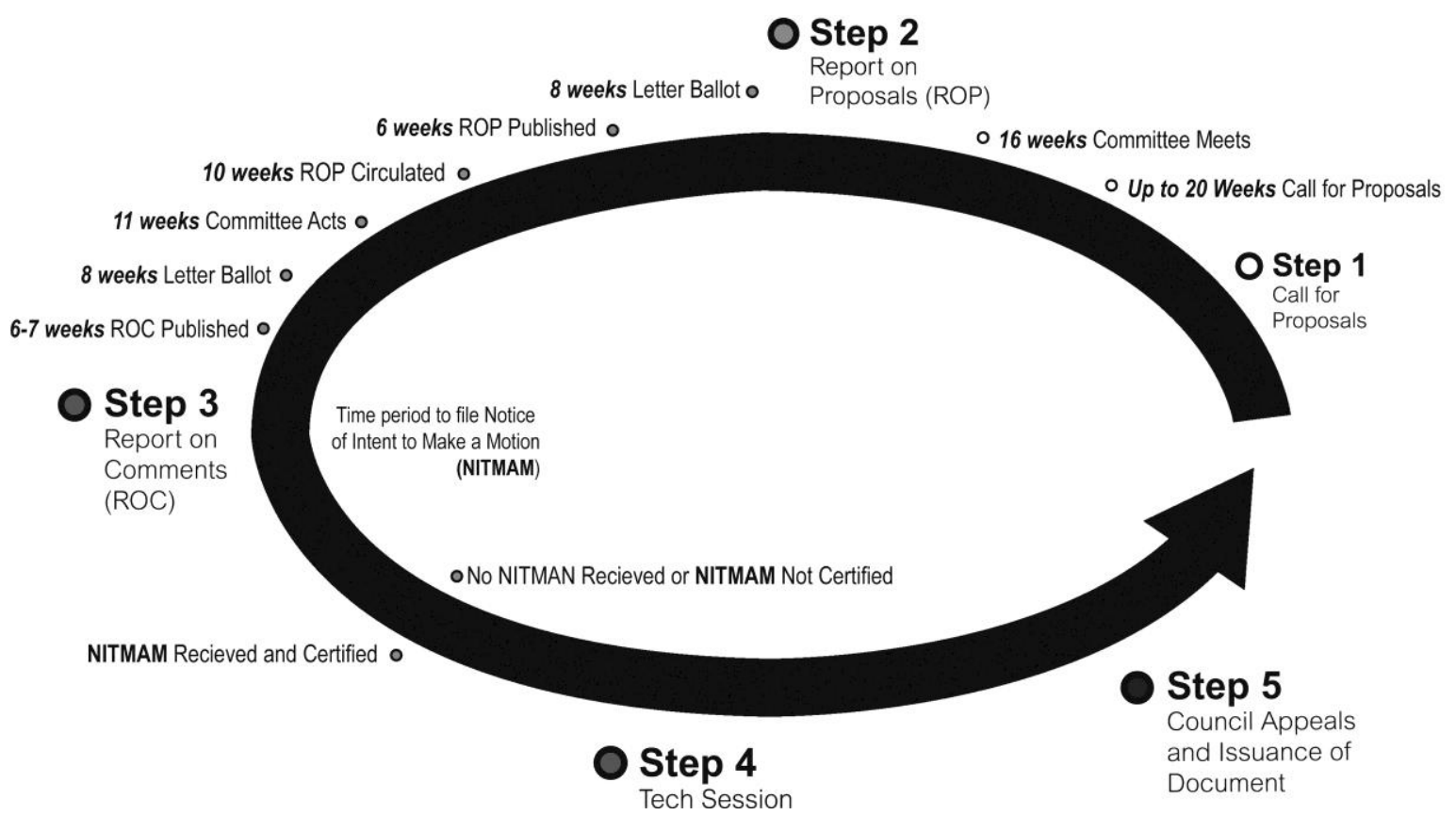


Table 1: Key events in institutional work

\section{Episode 1: Institutional work of creation}
1990, April
Standards Council votes to grant the request of ESE manufacturers to establish a new Technical Committee on Lightning Protection Systems Using Early Streamer Emission (ESE) Air Terminals (proposed NFPA-781).
1991, January Technical Committee for proposed NFPA-781 forms.
1991, October
Standards Council approves the Scope of NFPA-781 Technical Committee.
1993, October
Standards Council rejects request from ESE opponent to withdraw proposed NFPA-781 from current revision cycle.
1993, November
Proposed NFPA-781 published for public review and comment in the 1993 Fall
Meeting Technical Committee Reports. NFPA membership votes to return document to committee for further study.
1993, December ESE proponents petition Standards Council to reject the vote of the Association membership and immediately issue NFPA-781
1994, January Standards Council rejects ESE proponents' petition. Council defers ruling on issuance of Standard and seeks independent third party review.
1995, April Independent literature review and technical analysis (NIST Report) made available.
1995, July Following public hearing and review of NIST Report, Standards Council votes to discharge Technical Committee on ESE Air Terminals.

\section{Episode 2: Institutional Work of Disruption}

1995, May Motion at NFPA Annual Meeting by ESE proponents that NFPA-780 Lightning Protection Code be withdrawn and no longer issued as a Standard is defeated.

1995, July Standards Council votes to deny subsequent complaint and issue NFPA-780. Revisions to title and scope made.

\section{Episode 3: Creation re-visited}

1998, October Standards Council votes to grant request of ESE proponents to reopen proceedings for issuance of NFPA-781 and conduct de novo review of evidence by an independent panel.

1999, September Report of the Third Party Independent Evaluation Panel on ESE technology becomes available (Bryan Report).

2000, April Following public hearing and review of Bryan Report, Standards Council votes not to issue a standard for ESE lightning protection systems and not to initiate further ESE standard development.

\section{Episode 4: Disruption re-visited}

2000, May

2000, July

2000, September

2000, October

2001, June

2001, October
Motion to return the proposed 2000 edition of NFPA-780 to committee is defeated in floor debate at Technical Session, and NFPA-780 is retained as a standard.

Standards Council upholds appeals by ESE proponents, votes not to proceed with the issuance of the proposed 2000 edition of NFPA-780 and announces intention to withdraw 1997 edition and terminate the project on lightning protection.

Public comment is invited before final action on NFPA-780.

Council votes to defer action on NFPA-780 and invites substantiation of NFPA780 and traditional lightning protection systems.

Independent literature reviews and analyses of traditional lightning protection systems are submitted.

Standards Council votes to continue the project on Lightning Protection and issue the 2000 edition of NFPA-780 for conventional lightning protection systems. 


\begin{tabular}{ll}
\hline $\begin{array}{l}\text { Justification } \\
\text { Principles }\end{array}$ & Definition \\
\hline Consensus & $\begin{array}{l}\text { Process of maximum participation and substantial } \\
\text { agreement by a broad range of interests within a given } \\
\text { technological field, and determined by ballot }\end{array}$
\end{tabular}

Impartial Solutions should be application-independent and

solutions impartial so that they do not favour certain companies, technologies or markets

Innovation

Proven efficacy:

Scientific merit

Process and solution must promote creativity and innovation in the development of new methods and technologies

Solution is scientifically sound, based on independent review and reliable sources

Proven efficacy:

Empirical

evidence

Solution is underpinned by empirical (test)

evidence, based on independent review and reliable sources

Procedural fairness

\section{Illustrations of Deployment of Principles by ESE Challengers}

Mobilisation of Australian, French and U.S. manufacturers

ESE standard claimed to be in the interests of an "entire group of companies" in "a new segment of the Lightning Protection industry"

"Failure of the NFPA" to create an ESE technical committee would "have an anticompetitive effect and [would] hurt the consumer in the marketplace."

"[The ESE technology] is based on a truly different concept, and different design philosophy."

Provision of supporting documentation from the French Gimelec companies, based on research in high voltage laboratories and a list of French scientists who participated - "some of whom [the ESE manufacturers] consider to be very eminent type scientists".

The Australian entrepreneur described a programme of research measuring ESE performance relative to Franklin rods "under a live active thunderstorm", which is "the best possible testing" and stressing the sophisticated nature of these tests - "something that five years ago wouldn't have been possible"

A new Technical Committee comprising individuals who "know about the principles on which the technology is based" was sought to alleviate bias.

"[It would not be] appropriate to impose a requirement on [ESE systems] beyond that which has been imposed on the Faraday system." 
Harm mitigation

Solutions should minimise the possibility and effects of fire and related hazards
Users around the world were seeking improved lightning protection. The absence of an ESE standard would mean that these systems will be installed and unregulated, potentially placing the user at risk. Regulation of this new segment of the industry was thus sought. 


\section{Endnotes}

${ }^{1}$ Garud et al., "Institutional entrepreneurship as embedded agency"

2 DiMaggio, "Interest and agency"

${ }^{3}$ Foster et.al., "History as social memory assets"; Suddaby et al., "Rhetorical history"

${ }^{4}$ Garud et al, "Institutional entrepreneurship"; Macguire et al., "Institutional entrepreneurship in emerging fields"; Montiel and Husted, "The adoption of voluntary environmental management programs." But see Greenwood et al., "Institutional entrepreneurship in mature fields" and Greenwood et al., "Theorizing change"

${ }^{5}$ Battilana et al., "How actors change institutions"

${ }^{6}$ Lawrence et al., "Institutional Work"

${ }^{7}$ Lawrence and Suddaby, "Institutions and institutional work"

${ }^{8}$ Fligstein, "Social skill and institutional theory"

9 Battilana et al., "How actors change institutions"

${ }^{10}$ Examples include International Organisation for Standardization (ISO); Comité Europeén de Normalisation; British Standards Institute

${ }^{11}$ Velkar, "Transactions, standardisation and competition"

${ }^{12}$ Bhaskar, Realist Theory of Science

${ }^{13}$ Leca and Naccache, "A critical realist approach"

${ }^{14}$ Lawrence and Suddaby, "Institutions and institutional work"

15 Jepperson, "Institutions"

${ }^{16}$ DiMaggio and Powell, "Introduction”; Scott, Institutions and Organisations.

${ }^{17}$ Thornton and Ocasio, "Institutional logics"

${ }^{18}$ Leca and Naccache, "A critical realist approach" 632

${ }^{19}$ Scott, Institutions and Organisations

${ }^{20}$ Velkar, "Transactions, standardisation and competition"

${ }^{21}$ McGaughey, Narratives of Internationalisation; Suchman, "Managing legitimacy"

22 Oliver, "Antecedents of deinstitutionalisation"

${ }^{23}$ Barley and Tolbert, "Institutionalization and structuration"

${ }^{24}$ Lawrence and Suddaby, "Institutions and institutional work"

${ }^{25}$ DiMaggio, "Interest and agency"

${ }^{26}$ Sine and David, Institutions and Entrepreneurship, 19; Popp and Holt, "The presence of entrepreneurial opportunity" 
${ }^{27}$ Battilana et al., "How actors change institutions"

${ }^{28}$ Fligstein, "Social skill and institutional theory"

${ }^{29}$ Roscoe et al., "How does an old firm learn new tricks?"

${ }^{30}$ Battilana, "Agency and institutions"

${ }^{31}$ Suchman, "Managing legitimacy"

${ }^{32}$ Fligstein. "Social skill and institutional theory"

${ }^{33}$ Suddaby et al., "Rhetorical history"

${ }^{34}$ Foster et al., "History as social memory assets"

${ }^{35}$ Uman, "The Art and Science of Lightning Protection"

${ }^{36}$ Zipse, "Lightning protection systems"

${ }^{37}$ McGaughey. Narratives of Internationalisation

${ }^{38}$ Dacin and Dacin, "Traditions as institutionalized practice"

${ }^{39}$ Garud and Rappa, "A socio-cognitive model"

${ }^{40}$ Tobias, "The basis of conventional lightning protection systems"

${ }^{41}$ Uman and Rakov, “A critical review” 1089

${ }^{42}$ Sparks generated in laboratory settings are most commonly 1-3 meters in length (20 meters at most), compared to 5-10 kilometres for natural lightning

${ }^{43}$ Uman, "The Art and Science of Lightning Protection"

${ }^{44}$ NFPA-SCD, SC \#90-29

${ }^{45}$ COP 781-5, Fall 1993, 419

${ }^{46}$ COP 781-5, Fall 1993, 422

${ }^{47}$ Petition Re Proposed Standard 781 on Behalf of Heary Brothers, 7 December 1993, 6-7

${ }^{48}$ NFPA-SCM, D\#94-11

49 Van Brunt et al., "Early Streamer Emission Air Terminals" 24.

${ }^{50}$ NFPA-SCD, D\#95-26

${ }^{51}$ NFPA-SCD, D\#95-26

52 Van Brunt et al., "Early Streamer Emission Air Terminals"

${ }^{53}$ NFPA-SCD, D\#95-25

${ }^{54}$ NFPA-SCM, 18-21 July 1995, 3

${ }^{55}$ Interview, J.R. Gumley, Chairman, Global Lightning Technologies Pty Ltd, Hobart Australia, 1997

${ }^{56}$ NFPA, Decision of the Board of Directors on the Appeal of Heary Bros. Lightning Protection Co., Inc. and Lightning Preventor of America, Inc. re NFPA-780, 7 December 1995 
${ }^{57}$ Civil Action No. 96-2796 PHX/ROS in the United States District Court for the District of Arizona

${ }^{58}$ NFPA, Agreement of Settlement and Release between Heary Bros. Lightning Protection Co. and NFPA, 6 October 1998

${ }^{59}$ Bryan et al., "Report of the Third-Party"

${ }^{60}$ Bryan et al., Ibid, p. 28

${ }^{61}$ NFPA-SCD, D\#00-13

${ }^{62}$ NFPA-SCH, 18 July 2000, 246-247

${ }^{63}$ NFPA-SCD, D\# 00-22, 4

${ }^{64}$ Battilana, "Agency and Institutions"

${ }^{65}$ NFPA-SCD, D\# 00-30, 1

${ }^{66}$ NFPA-SCD, D\# 01-26

${ }^{67}$ Letter from Erico Inc. to NFPA Standards Council, 29 August 2001

${ }^{68}$ NFPA-TOH, 27 April 2000, 15

${ }^{69}$ NFPA, Standards Council Decision (Final) D\#05-11, 14 January 2005

${ }^{70}$ Suddaby and Greenwood, "Rhetorical strategies"

${ }^{71}$ NFPA-TOH, 27 April 2000, 62. Dates here cross-reference to episodes in Table 1.

72 NFPA-TOH, May 1995, 121

${ }^{73}$ NFPA-TOH, 27 April 2000, 123-124

74 NFPA-TOH, May 1995, 118-119

${ }^{75}$ Lawrence and Suddaby, "Institutions and institutional work"

${ }^{76}$ Anderson, Lightning Conductors

${ }^{77}$ Federal Interagency Lightning Protection User Group, “The Basis of Conventional Lightning Protection"

${ }^{78}$ Report of the Committee on Atmospheric and Space Electricity

${ }^{79}$ Hibbert and Huxham, "The past in play"

${ }^{80}$ Suchman, "Managing Legitimacy"

${ }^{81}$ NFPA-TOH, 27 April 2000, 123-124.

${ }^{82}$ Suddaby and Greenwood, "Rhetorical strategies of legitimacy"

${ }^{83}$ NFPA-TOH, 4 October 2001, p. 12-13

${ }^{84}$ Isaacson, Benjamin Franklin

${ }^{85}$ Foster, "History as Social Memory Assets"

${ }^{86}$ NFPA-TOH, 27 April 1990, 8 
${ }^{87}$ See McGaughey for a related discussion in the context of an Australian ESE manufacturer

${ }^{88}$ NFPA-TOH, May 1995, 107-108

89 NFPA-TOH, 18 July 1995, 152

${ }^{90}$ Lawrence and Suddaby, "Institutional Work"

${ }^{91}$ The various quotes in this paragraph are drawn from Anderson, Lightning Conductors, chapters 1-4.

92 Lawrence and Suddaby, "Institutions and institutional work"

${ }^{93}$ For a similar reframing, see Suddaby and Lawrence, "Rhetorical strategies of legitimacy"

94 Lawrence et al., "Institutional Work"

${ }^{95}$ Popp and Holt, "The presence of entrepreneurial opportunity" make similar observations regarding the nature of entrepreneurial opportunity.

${ }^{96}$ Foster et.al., "History as Social Memory Assets"; Suddaby et al. "Rhetorical History"

${ }^{97}$ Fligstein, "Social Skill"

${ }^{98}$ Suchman, "Managing Legitimacy"

${ }^{99}$ The arguments quoted in Table 2 are of ESE manufacturers recoded in NFPA-TOH, 24 April 1990. 